\title{
Axial Spondyloarthritis: Clinical Characteristics, Epidemiology, and General Approaches to Management
}

\author{
Authors: \\ Conall MacGearailt, *Gillian E. Fitzgerald \\ Department of Rheumatology, Galway University Hospital, Ireland \\ *Correspondence to GillianEl.Fitzgerald@hse.ie \\ Disclosure: $\quad$ The authors have declared no conflicts of interest. \\ Received: \\ 23.03.21 \\ Accepted: \\ 18.05.21 \\ Keywords: \\ Ankylosing spondylitis, axial spondyloarthritis (axSpA), clinical features, patient \\ education, review. \\ Citation: \\ EMJ Rheumatol. 2021;9[1]:105-114
}

\section{Abstract}

Axial spondyloarthritis (axSpA) is a chronic inflammatory condition, with an age of onset almost exclusively under 45 years. Although symptoms are initially centred on the sacroiliac joints and spine, extraspinal manifestations are common and add considerably to the burden of disease. In this narrative review, the authors provide an update on the epidemiology of the disease and briefly summarise the pathophysiology. The authors detail the clinical manifestations of axSpA, including an overview of axial features, peripheral manifestations, and associated comorbidities. The authors outline the current outcome measures used in the assessment of patients. Finally, the authors provide a summary of the general principles of treatment and briefly outline the role of patient education in the management of individuals with axSpA.

\section{INTRODUCTION}

Axial spondyloarthritis (axSpA) is a chronic inflammatory condition that predominantly affects the sacroiliac joints and spine. It is a type of spondyloarthritis (SpA) that refers to a group of inter-related conditions including psoriatic arthritis (PsA), reactive arthritis, and arthritis associated with inflammatory bowel disease (IBD). ${ }^{1}$ Ankylosing spondylitis (AS) was the prototype SpA condition, diagnosed when characteristic changes of sacroiliitis are seen on an X-ray of the pelvis in conjunction with clinical criteria. ${ }^{2}$ It has been increasingly recognised that the characteristic radiographic changes of AS could take many years to develop, thus excluding a large group of people with suggestive symptoms, but normal X-rays. This led to the development of the Assessment of SpondyloArthritis international Society (ASAS) criteria in 2009, which recognised a radiographic stage broadly similar to AS, as well as a nonradiographic stage $(n r-a x S p A){ }^{3}$ This allowed individuals with earlier or less severe disease, who had suggestive clinical features and sacroiliitis on magnetic resonance imaging, to be classified as axSpA.

\section{EPIDEMIOLOGY}

AxSpA typically occurs in the third decade of life, and almost exclusively before 45 years of age. Historically, AS was considered to be a maledominated disease, with early literature reporting 
ratios of up to 10:1. However, more recent estimates put that ratio at closer to 3:1, with virtually no difference seen in the distribution of $n r-a x S p A$ between men and women. ${ }^{4}$

The major histocompatibility complex 1 human leukocyte antigen (HLA)-B27 allele is strongly associated with axSpA, and is found in $74-89 \%$ of affected individuals. ${ }^{5}$ The prevalence of axSpA is typically greater in populations with a higher background prevalence of HLA-B27.4 In Europe, the prevalence of HLA-B27 varies from $2 \%$ to $25 \%$ and is highest in Scandinavian countries. ${ }^{6}$ In contrast, HLA-B27 is rare in Japan and Arab countries, and almost non-existent in some populations such as indigenous tribes of South America. ${ }^{6}$ The Pawaia tribe in Papua New Guinea has the highest prevalence of HLA-B27 worldwide, with $53 \%$ of people affected. ${ }^{7}$

In 2016, Stolwijk et al. ${ }^{8}$ systematically estimated the global prevalence of axSpA between $0.36 \%$ and $0.70 \%$ and $A S$ between $0.20 \%$ and $0.25 \%$. The lowest prevalence was in Southeast Asia with a pooled prevalence of $0.2 \%$ and the highest in the northern Arctic communities. The native Eskimo (Inuit) population demonstrated a strikingly high prevalence of SpA of $2.5 \%$, with the prevalence of HLA-B27 also high, affecting up to $40 \%$ of the study population. ${ }^{9}$

However, in reality it is difficult to know the true prevalence of axSpA because of a lack of population studies and a continued underrecognition and underdiagnosis of axSpA. In addition, delay to diagnosis has been a longstanding challenge in the management of axSpA, with mean delays of approximately 7 years reported in a large meta-analysis of 23,883 individuals. ${ }^{10}$ Long delays to diagnosis are associated with a number of worse outcomes in axSpA, such as more active disease, greater chance of disability, and increased healthcare costs." The delay to diagnosis is more common in women than men. ${ }^{10}$ Women are less likely to report typical inflammatory back-pain symptoms, and more likely to report widespread pain; misdiagnoses such as fibromyalgia (FM) are more commonly made in the female population, ${ }^{12}$ which may also exacerbate diagnostic delay. A negative HLA-B27 also appears to be associated with diagnostic delay. ${ }^{13}$ If undiagnosed or undertreated, axSpA may lead to continuous pain, stiffness, and fatigue, and may ultimately lead to a reduction in quality of life ( $Q \circ L)$.

\section{PATHOPHYSIOLOGY}

Most pathogenesis studies to date have focused on AS rather than axSpA. It appears to develop through complex interactions between genetic background and environmental factors. Studies performed on monozygotic twins and familial aggregation studies suggest that AS has a heritability of above 90\%.14,15 HLA-B27 positivity is also strongly linked with AS, occurring in only about $5 \%$ of the general population, but more than $90 \%$ of individuals with AS. ${ }^{16}$ Exactly how HLA-B27 predisposes to AS is not yet fully understood, but several hypotheses have been put forward: 17

1. Arthritogenic peptide hypothesis: the specific sequence of amino acids found in the peptide-binding groove of HLA-B27 might bind a peptide which elicits a cytotoxic T-cell response cross-reactive with a B27/selfpeptide combination, i.e., molecular mimicry. ${ }^{16}$

2. HLA-B27 misfolding hypothesis: it is thought that the specific sequence of amino acids in the peptide-binding groove causes a propensity for HLA-B27 to misfold in the endoplasmic reticulum, leading to a proinflammatory stress response; however, evidence to date is largely limited to rat studies. ${ }^{18}$

3. Cell-surface B27 free heavy chain expression and immune recognition hypothesis: HLA-B27 tends to form homodimers, which bind to free heavy chains expressed on the cell surface, thus triggering a pro-inflammatory process. ${ }^{16}$

However, despite this strong association, HLA-B27 contributes only 33\% of the total heritability of AS. ${ }^{16}$ Genome-wide association studies have additionally detected several genes associated with AS. $^{19}$ Barrier damage to the skin or gut surfaces may also be relevant to pathogenesis. $^{20}$ Microbial infection appears to act as a triggering factor. ${ }^{21}$ 
Table 1: Three separate criteria for inflammatory back pain.

\begin{tabular}{|c|c|c|}
\hline Calin criteria $^{25}$ & Berlin criteria ${ }^{22}$ & ASAS expert criteria ${ }^{26}$ \\
\hline $\begin{array}{l}\text { Age at onset }<40 \text { years } \\
\text { Duration of back pain }>3 \text { months } \\
\text { Insidious onset } \\
\text { Associated with morning stiffness } \\
\text { Improvement with exercise }\end{array}$ & $\begin{array}{l}\text { Morning stiffness }>30 \text { min } \\
\text { Improvement with exercise but not } \\
\text { with rest } \\
\text { Alternating buttock pain } \\
\text { Waking in second half of night } \\
\text { because of back pain }\end{array}$ & $\begin{array}{l}\text { Age at onset }<40 \text { years } \\
\text { Pain at night, with improvement upon } \\
\text { getting up } \\
\text { Insidious onset } \\
\text { Improvement with exercise } \\
\text { No improvement with rest }\end{array}$ \\
\hline $\begin{array}{l}\text { Criteria fulfilled if at least four of the } \\
\text { five criteria are present, with specificity } \\
\text { of } 85 \% \text { and sensitivity of } 95 \%\end{array}$ & $\begin{array}{l}\text { Criteria fulfilled if two or more } \\
\text { parameters are fulfilled, with a } \\
\text { sensitivity of } 81 \% \text { and specificity of } \\
70 \%\end{array}$ & $\begin{array}{l}\text { Criteria fulfilled if four out of five } \\
\text { parameters are present, with a } \\
\text { sensitivity of } 77 \% \text { and specificity of } \\
92 \%\end{array}$ \\
\hline
\end{tabular}

ASAS: Assessment of SpondyloArthritis international Society.

Italics refer to respective criteria fulfilment.

\section{CLINICAL FEATURES}

\section{Axial Symptoms}

Patients typically present with inflammatory back pain (IBP), characterised by an insidious onset of lower back and alternating buttock pain that worsens with inactivity and improves with exercise and non-steroidal anti-inflammatory drugs (NSAID). Patients may report waking at night with lower back pain, particularly in the latter stages of sleep. IBP is also associated with morning stiffness that usually lasts more than 30 minutes. ${ }^{22}$ Determining whether lower back pain is inflammatory or mechanical can be challenging because lower back pain is very common in the general population, with 38\% experiencing lower back pain for at least 1 day every year. ${ }^{23}$ However, of all those with chronic lower back pain, IBP represents only approximately 5\%. ${ }^{24}$ Many attempts have been made to classify IBP (Table 1), $, 22,25,26$ with the following features considered important in differentiating between IBP and other common causes of back pain: ${ }^{22}$

$>$ Age: onset of axSpA after the age of 45 years is exceedingly rare.

$>$ Duration of pain: non-IBP is often self-limiting.

> Onset of pain: non-IBP is often acute in onset.

$>$ Diurnal variation: pain and stiffness in axSpArelated IBP tends to be worse in the second half of the night and early morning.
> Response to exercise: IBP responds well to exercise, a feature characteristic of many inflammatory conditions.

> Location: alternating buttock pain can indicate inflammation of sacroiliac joints. ${ }^{22,26}$

\section{Peripheral Disease}

Peripheral arthritis can affect up to half of individuals with axSpA, has a higher prevalence in the Latin American population compared to other geographic regions, tends to be more common in the lower limbs, and is typically oligoarticular. ${ }^{27}$ Peripheral arthritis in axSpA may affect any joint, but is typically asymmetric. It is important to recognise peripheral arthritis, as its presence may direct management. Conventional synthetic disease-modifying antirheumatic drugs have a role in managing peripheral arthritis, whereas they are ineffective for axial disease.

Entheses are the sites of attachment of tendons or ligaments to bone, and enthesitis (inflammation of entheses) occurs in $44 \%$ of individuals with axSpA, with a predominance for lower limbs. ${ }^{27}$ The heel (Achilles tendon or plantar fascia) is the most common site of enthesitis in axSpA, with most affected individuals having an intermittent course. ${ }^{27}$ It can be difficult clinically to differentiate between enthesitis and arthritis, due to the anatomic overlap between entheses and joints. ${ }^{28}$ 
Dactylitis or 'sausage digit' involves inflammation of an entire digit (either a finger or toe), and is caused by flexor tenosynovitis, in combination with soft-tissue oedema. ${ }^{29}$ Dactylitis can occur in up to $8 \%$ of individuals with axSpA, ${ }^{27}$ although it is more commonly seen in PsA. ${ }^{30}$ Interestingly, a meta-analysis explored the difference in the prevalence of peripheral manifestations between patients with AS and nr-axSpA and found no significant differences between the two groups. ${ }^{31}$

\section{Extra-Articular Manifestations}

Acute anterior uveitis (AAU), IBD, and psoriasis (PsO) are three conditions that are overrepresented in axSpA and are thus considered extra-articular manifestations of the disease.

AAU is the most common extra-articular feature of $\operatorname{axSpA}$, with a reported prevalence of 26$33 \%{ }^{32}$ AAU associated with axSpA typically presents acutely, often with a 1- to 2-day prodrome, and tends to be unilateral, with circumlimbal hyperaemia, pain, photophobia, and visual impairment, with subsequent attacks often affecting the other eye. AAU more commonly occurs in a $H L A-B 27-p o s i t i v e ~ p a t i e n t ~ c o h o r t .{ }^{33}$ Visual prognosis in AAU associated with axSpA is excellent, with most individuals regaining full vision within 2 months. ${ }^{34}$

$\mathrm{PsO}$ is another notable feature of axSpA, affecting approximately $10 \%$ of individuals. ${ }^{32}$ This disease feature must be distinguished from a diagnosis of PsA, which may present similarly. Patients with axSpA tend to have more back pain at presentation and score higher on physician score global indices when compared to PsA. ${ }^{35}$ Interestingly, the presence of $\mathrm{PsO}$ in axSpA is an independent risk factor for increased entheseal damage. ${ }^{36}$

Clinically evident IBD is noted in $6-14 \%$ of AS patients, ${ }^{32}$ with Crohn's disease occurring more commonly than ulcerative colitis. However, microscopic evidence of IBD was noted in up to $60 \%$ of AS patients, suggesting a significant proportion of clinically silent disease. ${ }^{37}$ Faecal calprotectin is a non-specific marker for gut inflammation. In a 5-year longitudinal study, higher faecal calprotectin levels at baseline were associated with the development of Crohn's disease, as well as more severe AS disease clinically, but without any relationship to gut symptoms, suggesting that inflammation in the gastrointestinal tract and musculoskeletal system are linked. ${ }^{38}$

\section{COMORBIDITY IN AXIAL SPONDYLOARTHRITIS}

Mortality in axSpA is increased when compared with age- and sex-matched controls. ${ }^{39,40}$ Some of this excess mortality can be explained as a direct consequence of the disease, such as death because of neurological deficits from vertebral fractures. ${ }^{41}$ However, comorbid conditions, in particular cardiovascular disease, are shown to be a leading cause of death in axSpA. ${ }^{39,40}$

A comorbid condition can be defined as any distinct additional clinical entity that has existed or that may occur during the clinical course of an individual who has the index disease under study.

The ASAS-COMOSPA study was a large, multinational, cross-sectional study that outlined the profile of comorbidities occurring in individuals with $\mathrm{SpA} .{ }^{42}$ The most prevalent comorbidity was osteoporosis, affecting 13\% of the cohort. Diagnosis of osteoporosis in axSpA using dual-energy $\mathrm{X}$-ray absorptiometry may be difficult in advanced structural disease because of the presence of osteoproliferation, which can falsely increase bone mineral density. Lateral views of the spine are a promising technique for overcoming this. ${ }^{43}$

Almost $4 \%$ of the ASAS-COMOSPA cohort had cardiovascular morbidity, ${ }^{42}$ with a lower prevalence in axSpA individuals compared with those with peripheral SpA. ${ }^{44}$ Hypertension and smoking have been shown to be more pervasive in an axSpA population. ${ }^{45}$

Depression is common in axSpA, with Zhao et al. reporting a prevalence of $15 \%$ showing at least moderate depression in a systematic review. ${ }^{46}$ Obesity is another comorbidity that is shown to be common in axSpA, affecting $15-27 \%$ of axSpA cohorts. ${ }^{47,48}$ Of note, patients with concomitant obesity tend to be less responsive to conventional therapy in axSpA. ${ }^{49}$

Comorbidities in axSpA are of clinical relevance, as they have been shown to add to the burden of disease. Increasing comorbidity burden is associated with more active disease and worse spinal mobility. ${ }^{47}$ The presence of comorbidities 
in SpA adversely affects physical function, work ability, QoL, and increases healthcare expenditure. ${ }^{47,50}$ Despite this known burden of comorbidities in axSpA, optimal screening for them is poor, with the ASAS-COMOSPA study demonstrating that only half of participants had an adequate assessment of their cardiovascular status, and optimal cancer screening was only performed in $11-44 \%$ of participants. ${ }^{42}$ Less than $20 \%$ of individuals with axSpA have an objective assessment of their bone mineral density. ${ }^{47}$ Treatment of comorbidities is also suboptimal, with less than one-quarter of a Dutch cohort of patients with AS treated for hypertension or hypercholesterolaemia achieving treatment targets. ${ }^{45}$

FM is a non-inflammatory comorbidity characterised by widespread pain and fatigue, with an estimated one-in-six prevalence in axSpA. ${ }^{51}$ Patients who met the criteria for FM reported significantly worse disease activity and function, as well as a lower QoL. ${ }^{52}$ In patientreported outcomes (PRO), low disease activity or disease remission is less likely to be achieved in patients with FM.53 The presence of FM appears to have a negative impact on response to biologics, ${ }^{54}$ with shorter retention times. ${ }^{55}$ For this reason, it is important to screen patients with AxSpA for FM because it may affect patient outcomes.

\section{OUTCOME MEASURES}

AxSpA is a complex multifaceted condition, and assessment of outcomes must reflect this. A number of validated outcome measures have been developed in axSpA, which deliver a comprehensive overview, subjectively and objectively, of many different domains of disease. Here, the authors collate scoring systems in axSpA that detail disease activity, patient function, QoL, radiological assessment, as well as objective measurement of enthesitis and dactylitis.

\section{Bath Ankylosing Spondylitis Disease Activity Index}

The Bath Ankylosing Spondylitis Disease Activity Index (BASDAI) is a validated PRO that measures fatigue, spinal pain, peripheral joints, enthesopathy, and early-morning stiffness severity and duration on a scale of 0-10. ${ }^{56}$ Scores of 4 or greater suggest active disease, which may require alteration of therapy. ${ }^{57}$ The benefit of the BASDAl is that it is a simple, patient-focused assessment assessing a wide variety of axSpA features. One of its drawbacks is that objective evidence of inflammation such as C-reactive protein (CRP) or erythrocyte sedimentation rate (ESR) is not assessed in the BASDAI. While the BASDAl did not initially include nr-axSpA patients, it has since been suggested that it may also be used in this patient cohort. ${ }^{58}$

\section{Bath Ankylosing Spondylitis Functional Index}

The Bath Ankylosing Spondylitis Functional Index (BASFI) is a patient-reported assessment for everyday tasks, also scored on a scale of 0-10, using either a numerical or a visual analogue. ${ }^{59}$ This scoring tool is validated, quick and easy to use, and sensitive to changes in the disease. ${ }^{60}$ Similar to the BASDAl, this tool had initially been validated for AS and not nr-axSpA.

\section{Ankylosing Spondylitis Disease Activity Score}

The Ankylosing Spondylitis Disease Activity Score (ASDAS) was developed to include objective measures of inflammation that were not present in the BASDAI. It is closely associated with the Disease Activity score utilised in rheumatoid arthritis. The ASDAS incorporates three questions from the BASDAI (back pain, peripheral pain, and early-morning stiffness), patient global assessment, and acute-phase reactant using either ESR or CRP.61,62 Disease activity is subsequently classified into inactive, moderate, high, and very high disease activity states. ${ }^{63}$ The ASDAS has demonstrated validity and is more sensitive to treatment than previous scoring metrics. ${ }^{64}$ A notable disadvantage of the ASDAS is CRP or ESR may not be available on clinic days. Also, a raised CRP or ESR may not always reflect disease activity.

\section{Health Assessment Questionnaire}

The Health Assessment Questionnaire (HAQ) is a PRO questionnaire, which initially focused on pain, disability, medication effects, costs, and mortality. Answers are assessed from 0-3, where 3 indicates more severe disability. ${ }^{65}$ 


\section{Ankylosing Spondylitis Quality of Life}

The Ankylosing Spondylitis Quality of Life (ASQoL) questionnaire is comprised of 18 questions that aim to accurately assess QoL in patients with AS. ${ }^{66}$ It may also be used in $\mathrm{nr}$ axSpA. Each question is yes/no, with each 'yes' scoring one point. The points are summed, giving a total score between 0 and 18, with a higher score signifying a worse QoL. Difficulties with the AS QoL include failure of a yes/no answering system to fully encapsulate a patient's sense of wellbeing.

\section{Bath Ankylosing Spondylitis Metrology Index}

The Bath Ankylosing Spondylitis Metrology Index (BASMI) differs from previous scoring systems in that it assesses objective clinical measurements rather than PRO. BASMI assesses spinal mobility on a scale of 0-10.67 The composite score measures cervical rotation, wall-to-tragus distance, lateral flexion, modified Schober's test, and intermalleolar distance. Higher scores reflect more significant restriction. It is a quick and reproducible assessment that demonstrates high sensitivity.

\section{Modified Stoke Ankylosing Spondylitis Spinal Score}

The Modified Stoke Ankylosing Spondylitis Spinal Score (mSASSS) was developed to assess radiographic changes in $A S .{ }^{68}$ It uses lateral spinal $X$-rays to quantify radiological damage on the anterior aspect of the spine from the lower border of $\mathrm{C} 2$ to the upper border of T1, plus the lower border of T12, all five lumbar vertebrae, and upper sacrum. This scale scores each vertebra border on a $0-3$ scale: 0 is normal; 1 shows sclerosis erosions or squaring; 2 is for obvious syndesmophyte formation; and 3 shows total bridging syndesmophyte formation. A summed score of $\mathrm{O}$ indicates a normal spine, and 72 a completely ankylosed, or 'bamboo', spine.

\section{Maastricht Ankylosing Spondylitis Enthesitis Score}

The Maastricht Ankylosing Spondylitis Enthesitis Score (MASES) is a scoring system of enthesopathy in patients with spondyloarthritis. Thirteen sites are assessed for discomfort on clinical examination in binary terms of tender or non-tender. ${ }^{69}$ This scoring system is more userfriendly than previous enthesitis measurements such as the Mander Enthesis Index (MEI). High enthesitis scores correlate well with high disease activity scores.

\section{Leeds Dactylitis Instrument}

The Leeds Dactylitis Instrument (LDI) is a validated clinical measurement of dactylitis. Dactylitis was defined as an increase of $10 \%$ or more of the size of the contralateral unaffected digit. $^{70}$ Measurement of degree of tenderness is also assessed clinically in order to complete the score. High scores are associated with worse dactylitis.

\section{GENERAL TREATMENT OVERVIEW}

Although a detailed overview of treatment is beyond the scope of this narrative review, the authors here outline the general principles of management of axSpA, based on existing recommendations (Figure 1). ${ }^{58,71}$ Briefly, the management of axSpA may be classified into non-pharmacological and pharmacological treatment, and treatment should be tailored according to the manifestations of the disease, the severity of symptoms, the clinical status of the patient, and the expectations and wishes of the patient. ${ }^{58}$ The importance of regular exercise and avoiding smoking must be emphasised to each patient, regardless of other treatment modalities. If the patient is symptomatic, regular NSAIDs are typically the first line of pharmacological treatment. If there is insufficient response with NSAIDs, patients with predominantly axial disease should be assessed for biologic diseasemodifying anti-rheumatic drugs. Currently, antiTNFs, anti-IL-17, and JAK inhibitors are licensed for axSpA treatment (Table 2).

\section{THE ROLE OF THE PATIENT IN DISEASE MANAGEMENT}

For too long, patients were often excluded from decisions regarding management of their condition. This has been addressed with the publication of the European League Against Rheumatism (EULAR) recommendations for patient education in inflammatory arthritis. ${ }^{72}$ Shared decision-making between the patient and rheumatologist is now an overarching principle in the recommended management of axSpA. ${ }^{58}$ 


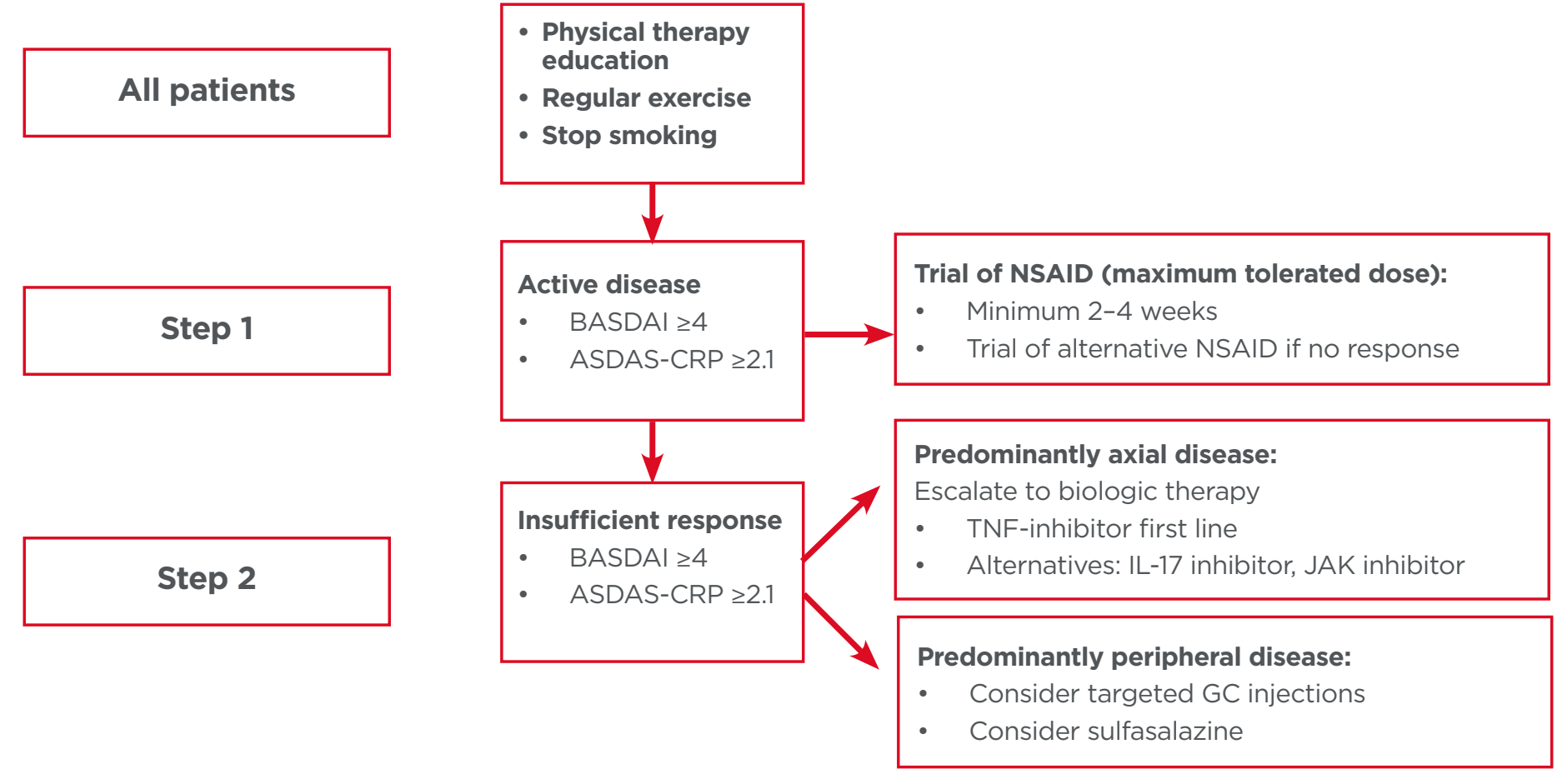

Figure 1: Steps for all patients taking part in physical therapy education, regular exercise, and who have stopped smoking.

ASDAS-CRP: Ankylosing Spondylitis Disease Activity Score-C-reactive protein; BASDAl: Bath Ankylosing Spondylitis Disease Activity Index; GC: glucocorticoid; NSAID: non-steroidal anti-inflammatory drug.

Table 2: Indications for biologics and JAK inhibitors.

\begin{tabular}{|c|c|c|c|c|c|}
\hline & Axial SpA & $\begin{array}{c}\text { Acute anterior } \\
\text { uveitis }\end{array}$ & Psoriasis & Crohn's disease & Ulcerative colitis \\
\hline Infliximab & Yes & Yes & Yes & Yes & Yes \\
\hline Adalimumab & Yes & Yes & Yes & Yes & No \\
\hline Etanercept & Yes & No & Yes & Yes & Yes \\
\hline Certolizumab & Yes & Yes & Yes & No & No \\
\hline Golimumab & Yes & Yes & Yes & No \\
\hline Secukinumab & Yes & No & Yes & Insufficient data & No \\
\hline Upadacitinib & Yes & Insufficient data & No & Yes \\
\hline Tofacitinib & No & Insufficient data & & & \\
\hline
\end{tabular}

SpA: spondyloarthritis.

To ensure that the patient can partake in all elements of this shared decision, education is key and refers to all activities that ensure an individual is well-informed about their condition, from education about treatment options to general health education and health promotion. ${ }^{72}$ Patient education, which can range from patient information leaflets to structured educational programmes, has been shown to increase adherence to treatment and promote patient self-management. ${ }^{73}$

The rheumatology nurse plays a key role in educating patients, with the updated 2018 
EULAR guidelines recognising the importance of rheumatology-trained nurses in providing needsbased education to individuals affected with chronic inflammatory arthritis. ${ }^{74}$ The Educational Needs Assessment Tool (ENAT) is one instrument that can accurately assess an individual's educational need and has been validated in many rheumatic conditions, including $\mathrm{AS} .{ }^{75}$ Using the results of the ENAT to guide the education of a patient can lead to improved outcomes. ${ }^{76}$ However, the ENAT alone is not sufficient, and the focus should be placed on individualised patient education, which should be tailored according to their needs. $^{74}$

One area where patient education is particularly key is in promoting the role of physical exercise in axSpA. Although the most effective exercise protocol in axSpA has not been clearly established, physical exercise is shown to improve disease activity and physical function in individuals with SpA. Despite this, physical activity is lower in adults with axSpA compared to the general population, with higher disease activity levels in those who are less physically active. ${ }^{77}$ Many individuals with axSpA lack motivation to partake in physical activity, even when aware of the benefits. ${ }^{78}$ Additionally, many individuals with rheumatic conditions are unaware of physical activity guidelines. ${ }^{79}$ A 3-month behavioural intervention in axSpA that incorporated motivational interviewing techniques resulted in better QoL, spinal mobility, and physical activity levels in patients with axSpA compared to a control group, which was sustained at Month $6 .^{80}$ This highlights the positive role that patient education can play in the management of axSpA.

\section{CONCLUSION}

In summary, axSpA is a chronic inflammatory condition, with both spinal and extraspinal manifestations. Recognition of IBP can be challenging, but the most recent ASAS IBP criteria have increased the sensitivity and specificity of the classification criteria. HLA-B27 is thought to play a significant role in the pathophysiology, but more research is needed to fully elucidate the pathways. Awareness of extraspinal manifestations of axSpAis is low, as shown by the infrequent screening that occurs. Regularly assessing multiple different disease outcomes with validated tools is an important part of managing axSpA, and assessing the effect of treatment. Enhancing patient involvement in their own management is also key.

\section{References}

1. Moll $\mathrm{J}$ et al. Associations between ankylosing spondylitis, psoriatic arthritis, Reiter's disease, the intestinal arthropathies, and Behcet's syndrome. Medicine (Baltimore). 1974;53:343-64.

2. van der Linden $\mathrm{S}$ et al. Evaluation of diagnostic criteria for ankylosing spondylitis. A proposal for modification of the New York criteria. Arthritis Rheum. 1984;27:361-8.

3. Rudwaleit M. et al. The development of Assessment of SpondyloArthritis international Society classification criteria for axial spondyloarthritis (part II): validation and final selection. Ann Rheum Dis. 2009;68:777-83.

4. van Tubergen A. The changing clinical picture and epidemiology of spondyloarthritis. Nat Rev Rheumatol. 2014;11(2):110-8.

5. Poddubnyy D, Sieper J. Similarities and differences between nonradiographic and radiographic axial spondyloarthritis: a clinical, epidemiological and therapeutic assessment. Curr Opin Rheumatol.
$2014 ; 26(4): 377-83$.

6. Khan MA. HLA-B27 and its subtypes in world populations. Curr Opin Rheumatol. 1995;7(4):263-9.

7. Bhatia $\mathrm{K}$ et al. Antigen and haplotype frequencies at three human leucocyte antigen loci (HLA-A, -B, -C) in the Pawaia of Papua New Guinea. Am J Phys Anthropol. 1988;75(3):329-40.

8. Stolwijk $C$ et al. Global prevalence of spondyloarthritis: a systematic review and meta-regression analysis. Arthritis Care Res (Hoboken). 2016;68(9):1320-31.

9. Boyer GS et al. Prevalence of spondyloarthropathies in Alaskan Eskimos. J Rheumatol. 1994;21(12):2292-7.

10. Jovani $\vee$ et al. Understanding how the diagnostic delay of spondyloarthritis differs between women and men: a systematic review and metaanalysis. J Rheumatol. 2017;44(2):174-83.

11. Barnett R et al. Axial spondyloarthritis 10 years on: still looking for the lost tribe. Rheumatology (Oxford). 2020;59(Suppl 4):iv25-37.

12. Ogdie A et al. Real-world patient experience on the path to diagnosis of ankylosing spondylitis. Rheumatol Ther. 2019;6:255-67.

13. Fallahi S, Jamshidi AR. Diagnostic delay in ankylosing spondylitis: related factors and prognostic outcomes. Arch Rheumatol. 2015;31(1):24-30.

14. Brown MA et al. Susceptibility to ankylosing spondylitis in twins: the role of genes, HLA, and the environment. Arthritis Rheum. 1997;40:1823-8.

15. van der Linden $\mathrm{S}$ et al. The risk of developing ankylosing spondylitis in HLA-B27 positive individuals: a family and population study. $\mathrm{Br} \mathrm{J}$ Rheumatol. 1993;22:18-9.

16. Bowness P. HLA-B27. Annu Rev Immunol. 2015;33:29-48.

17. Colbert $R$ et al. HLA-B27 misfolding and ankylosing spondylitis. Mol 
Immunol. 2014;57:44-51.

18. Turner MJ et al. HLA-B27 misfolding in transgenic rats is associated with activation of the unfolded protein response. J Immunol. 2005;175(4):2438-48

19. Ranganathan $\vee$ et al. Pathogenesis of ankylosing spondylitis - recent advances and future directions. Nat Rev Rheumatol. 2017;13:359-67.

20. Sieper J, Poddubnyy D. Axial spondyloarthritis. Lancet. 2017;390:73-84

21. Zhu W et al. Ankylosing spondylitis: etiology, pathogenesis, and treatments. Bone Res. 2019;7(22):22.

22. Rudwaleit $M$ et al. Inflammatory back pain in ankylosing spondylitis: a reassessment of the clinical history for application as classification and diagnostic criteria. Arthritis Rheum 2006:54(2):569-78.

23. Hoy $D$ et al. A systematic review of the global prevalence of low back pain. Arthritis Rheum. 2012:64(6):2028-37.

24. Underwood MR, Dawes P. Inflammatory back pain in primary care. Br J Rheumatol. 1995;34(11):1074-7.

25. Calin A et al. Clinical history as a screening test for ankylosing spondylitis. JAMA. 1977;237(24):2613-

26. Sieper J et al. New criteria for inflammatory back pain in patients with chronic back pain: a real patient exercise by experts from the Assessment of SpondyloArthritis international Society (ASAS). Ann Rheum Dis. 2009;68(6):784-8.

27. López-Medina $C$ et al. Prevalence and distribution of peripheral musculoskeletal manifestations in spondyloarthritis including psoriatic arthritis: results of the worldwide, cross-sectional ASAS-PerSpA study RMD Open. 2021;7(1)

28. Schett $G$ et al. Enthesitis: from pathophysiology to treatment. Nat Rev Rheumatol. 2017:13(12):731-41.

29. Olivieri I et al. What is the primary lesion in SpA dactylitis? Rheumatology. 2008;47(5):561-2.

30. Kaeley GS et al. Dactylitis: a hallmark of psoriatic arthritis. Semin Arthritis Rheum. 2018;48(2):263-73.

31. de Winter JJ et al. Prevalence of peripheral and extra-articular disease in ankylosing spondylitis versus nonradiographic axial spondyloarthritis: a meta-analysis. Arthritis Res Ther. 2016;18:196

32. Stolwijk C et al. Prevalence of extraarticular manifestations in patients with ankylosing spondylitis: a systematic review and meta-analysis. Ann Rheum Dis. 2015;74(1):65-73.

33. Rademacher $\mathrm{J}$ et al. Uveitis in spondyloarthritis. Ther Adv Musculoskelet Dis. 2020;12.

34. Rosenbaum JT. Uveitis in spondyloarthritis including psoriatic arthritis, ankylosing spondylitis, and inflammatory bowel disease. Clin Rheumatol. 2015;34(6)999-1002.

35. Feld $\mathrm{J}$ et al. Is axial psoriatic arthritis distinct from ankylosing spondylitis with and without concomitant psoriasis? Rheumatology. 2019;59(6):1340-6.

36. Solmaz D et al. Psoriasis is an independent risk factor for entheseal damage in axial spondyloarthritis. Semin Arthritis Rheum. 2020;50:42-7.

37. Van Praet L et al. Microscopic gut inflammation in axial spondyloarthritis: a multiparametric predictive model. Ann Rheum Dis. 2013;72:414-7.

38. Klingberg $\mathrm{E}$ et al. A longitudinal study of fecal calprotectin and the development of inflammatory bowel disease in ankylosing spondylitis. Arthritis Res Ther. 2017;19:21.

39. Exarchou $\mathrm{S}$ et al. Mortality in ankylosing spondylitis: results from a nationwide population-based study. Ann Rheum Dis. 2016;75:1466-72.

40. Haroon $\mathrm{N}$ et al. Patients with ankylosing spondylitis have increased cardiovascular and cerebrovascular mortality: a population-based study. Ann Intern Med. 2015;163(6):409-16.

41. Wysham KD et al. Cervical spinal fracture and other diagnoses associated with mortality in hospitalized ankylosing spondylitis patients. Arthritis Care Res (Hoboken). 2017;69(2):271-7.

42. Molto A et al. Prevalence of comorbidities and evaluation of their screening in spondyloarthritis: results of the international cross-sectional ASAS-COMOSPA study. Ann Rheum Dis. 2016;75:1016-23

43. Fitzgerald $\mathrm{G}$ et al. Measuring bone density in axial spondyloarthropathy: time to turn things on their side? Int $J$ Rheum Dis. 2020:23:358-66.

44. Lopez-Medina C et al. Cardiovascular risk factors in patients with spondyloarthritis from Northern European and Mediterranean countries: an ancillary study of the ASAS-COMOSPA project. Joint Bone Spine. 2018;85:447-53.

45. Heslinga SC et al. Cardiovascular risk management in patients with active ankylosing spondylitis: a detailed evaluation. BMC Musculoskelet Disord. 2015;16:80.

46. Zhao S et al. The prevalence of depression in axial spondyloarthritis and its association with disease activity: a systematic review and meta-analysis. Arthritis Res Ther 2018:20:140.

47. Fitzgerald $\mathrm{G}$ et al. Multimorbidity is common in axial spondyloarthropathy and is associated with worse disease outcomes: results from the ASRI cohort. J Rheumatol. 2019;47(2):21826.

48. Bindesbøll $\mathrm{C}$ et al. Obesity increases disease activity of Norwegian patients with axial spondyloarthritis: results from the European map of axial spondyloarthritis survey. Curr Rheumatol Rep. 2020;22:43.

49. Micheroli R et al. Impact of obesity on the response to tumor necrosis factor inhibitors in axial spondyloarthritis. Arthritis Res Ther. 2017;19:164.

50. Nikiphorou $\mathrm{E}$ et al. Association of comorbidities in spondyloarthritis with poor function, work disability, and quality of life: results from the Assessment of SpondyloArthritis international Society comorbidities in spondyloarthritis study. Arthritis Care Res (Hoboken). 2018;70:1257-62.

51. Jones $\mathrm{G}$ et al. The prevalence of fibromyalgia in axial spondyloarthritis. Rheumatol Int. 2020;40:1581-91.

52. Macfarlane GJ et al. Co-occurrence and characteristics of patients with axial spondyloarthritis who meet criteria for fibromyalgia: results from a UK national register. Arthritis Rheumatol (Hoboken, NJ). 2017;69(11):2144-50.

53. Mease PJ. Fibromyalgia, a missed comorbidity in spondyloarthritis: prevalence and impact on assessment and treatment. Curr Opin Rheumatol. 2017;29(4):304-10.

54. Moltó A et al. Evaluation of the impact of concomitant fibromyalgia on TNF alpha blockers' effectiveness in axial spondyloarthritis: results of a prospective, multicentre study. Ann Rheum Dis. 2018;77:533-40.

55. Bello $\mathrm{N}$ et al. Evaluation of the impact of fibromyalgia in disease activity and treatment effect in spondyloarthritis. Arthritis Res Ther. 2016;18:42.

56. Garrett S et al. A new approach to defining disease status in ankylosing spondylitis: the Bath Ankylosing Spondylitis Disease Activity Index. J Rheumatol. 1994;21:2286-91.

57. Braun J et al. International ASAS consensus statement for the use of anti-tumour necrosis factor agents in patients with ankylosing spondylitis. Ann Rheum Dis. 2003;62:817-24.

58. van der Heijde D et al. 2016 update of the ASAS-EULAR management recommendations for axial spondyloarthritis. Ann Rheum Dis. 2017:76:978-91.

59. Calin A et al. A new approach to defining functional ability in ankylosing spondylitis: the development of the Bath ankylosing spondylitis functional index. $J$ Rheumatol. 1994:21(12):2281-5.

60. Moncur C. Ankylosing spondylitis measures: the ankylosing spondylitis 
quality of life (ASQOL) scale, Bath ankylosing spondylitis disease activity index (BASDAI), Bath ankylosing spondylitis functional index (BASFI), Bath ankylosing spondylitis global score (BAS-G), Bath ankylosing spondylitis metrology index (BASMI), Dougados functional index (DFI), health assessment questionnaire for the spondyloarthropathies (HAQ-S), and revised Leeds disability questionnaire (RLDQ). Arthritis Care Res (Hoboken). 2003;49:S197-209.

61. Lukas C et al. Development of an ASAS-endorsed disease activity score (ASDAS) in patients with ankylosing spondylitis. Ann Rheum Dis. 2009;68(1):18-24.

62. van der Heijde D et al. ASDAS, a highly discriminatory ASAS-endorsed disease activity score in patients with ankylosing spondylitis. Ann Rheum Dis. 2009;68:1811-8.

63. Machado P et al. Ankylosing spondylitis disease activity score (ASDAS): defining cut-off values for disease activity states and improvement scores. Ann Rheum Dis. 2011;70(1):47-53.

64. Pedersen SJ et al. Responsiveness of the ankylosing spondylitis disease activity score (ASDAS) and clinical and MRI measures of disease activity in a 1-year follow-up study of patients with axial spondyloarthritis treated with tumour necrosis factor alpha inhibitors. Ann Rheum Dis. 2010;69:1065-71.

65. Fries JF et al. Measurement of patient outcome in arthritis. Arthritis Rheum.
1980;23(2):137-45.

66. Doward LC et al. Development of the ASQoL: a quality of life instrument specific to ankylosing spondylitis. Ann Rheum Dis. 2003;62:20-6.

67. Jenkinson TR et al. Defining spina mobility in ankylosing spondylitis (AS). The Bath AS Metrology Index. J Rheumatol. 1994;21:1694-8.

68. Creemers MC et al. Assessment of outcome in ankylosing spondylitis: an extended radiographic scoring system. Ann Rheum Dis. 2005;64:127-

69. Heuft-Dorenbosch L et al. Assessment of enthesitis in ankylosing spondylitis. Ann Rheum Dis. 2003;62:127-32.

70. Helliwell PS et al. Development of an assessment tool for dactylitis in patients with psoriatic arthritis. $J$ Rheumatol. 2005;32:1745-50.

71. Ward MM et al. 2019 Update of the American College of Rheumatology/ Spondylitis Association of America/ Spondyloarthritis Research and Treatment Network recommendations for the treatment of ankylosing spondylitis and nonradiographic axial spondyloarthritis. Arthritis Care Res (Hoboken). 2019;71:1285-99.

72. Zangi HA et al. EULAR recommendations for patient education for people with inflammatory arthritis. Ann Rheum Dis. 2015;74:954-62.

73. Candelas $\mathrm{G}$ et al. Benefit of health education by a training nurse in patients with axial and/or peripheral psoriatic arthritis: a systematic literature review. Rheumatol Int. 2016;36:1493-506.

74. Bech B et al. 2018 update of the EULAR recommendations for the role of the nurse in the management of chronic inflammatory arthritis. Ann Rheum Dis. 2020;79:61-8.

75. Ndosi $\mathrm{M}$ et al. Validation of the educational needs assessment too as a generic instrument for rheumatic diseases in seven European countries. Ann Rheum Dis. 2014;73(12):2122-9.

76. Ndosi M et al. Effects of needs-based patient education on self-efficacy and health outcomes in people with rheumatoid arthritis: a multicentre, single blind, randomised controlled trial. Ann Rheum Dis 2016;75(6):112632.

77. O'Dwyer T et al. Physical activity in spondyloarthritis: a systematic review. Rheumatol Int. 2015;35:393-404.

78. O'Dwyer T et al. Physical activity and exercise: perspectives of adults with ankylosing spondylitis. Journal of physical activity \& health. 2016;13:504-13.

79. O'Dwyer T et al. Physical activity guidelines: is the message getting through to adults with rheumatic conditions? Rheumatology (Oxford). 2014;53:1812-7.

80. O'Dwyer T et al. Behaviour change intervention increases physical activity, spinal mobility and quality of life in adults with ankylosing spondylitis: a randomised trial. J Physiother. 2017:63:30-9. 